\title{
Preparation, characterization and in vitro bioactivity of polyvinyl alcohol-hydroxyapatite biphasique membranes
}

\author{
Zuzana Balgováa, Martin Palou ${ }^{\mathrm{a}}$, Jaromír Wasserbauer ${ }^{\mathrm{a}}$, \\ Gabriela Lutišanováb, Jana Kozánkováb \\ ${ }^{a}$ Faculty of Chemistry, Brno University of Technology, Purkyňova 464/118, Brno 61200 \\ ${ }^{b}$ Faculty of Chemical and Food Technology, Slovak University of Technology in Bratislava, \\ Radlinského 9, 81237 Bratislava, Slovakia \\ balgova@fch.vutbr.cz
}

\begin{abstract}
Six membranes of polyvinyl alcohol (PVA) with various weight percent - $0 \%, 10 \%, 20 \%, 30 \%$, $40 \%$ and $50 \%$ of hydroxyapatite (HA) were prepared. Fourier Transform Infrared (FTIR) spectroscopy was used to identify the different functional groups in membrane composites. The surface morphology was examined through scanning electron microscope. The in vitro bioactivity tests in Simulated Blood Fluid (SBF) have been performed up to 28 days, especially for membrane containing $50 \mathrm{wt}$ \% HA. SEM was used to characterize surface microstructure of biocomposite membranes before and after immersion in SBF. It was observed the formation of clusters within membranes with increasing amount of HA particles due to hydrogen bond and also the agglomeration and crystal growth of HA particles during drying of membranes. The bioactivity was found increasing with time immersion of biocomposite materials in SBF solution.
\end{abstract}

Keywords: polyvinylalcohol, nanohydroxyapatite, bioactivity, simulated body fluid

\section{Introduction}

The development of composite biomaterials for an appropriate hard and soft tissue replacement implants is one of the most important topics in tissue engineering. Vallet-Regí (2009) has defined biomaterials as implantable materials that perform their function in contact with living tissues. Depending on the function to perform, they can be manufactured from very different metal, polymer, ceramic materials or their composites (Vallet-Regí, 2009).

Biocomposite materials based on polyvinylalcohol matrix reinforced with nanohydroxyapatite gel have been developed by Pan (2007) as an alternative biomaterial to titanium alloy in the replacement of diseased or damaged cartilage.

The applications of PVA as biomaterials to replace or to repair some hard and soft tissue like articular cartilage have increased in the last years. The main reason for the application of PVA, namely as injectable gel, is its excellent biocompatibility and bio tribological properties. (Kobayashi et al., 2005; Noguchi et al., 1991; Covert et al., 2003; Pan et al., 2007, Zheng et al., 1998).

However, the drawback of biomaterials based on PVA is their adhesion to the biological tissue. Indeed, PVA itself does not adhere biologically or chemically to tissue due to its bioinertness. Longterm fixation of PVA implant on the surface of living tissue by suture or any way is also difficult to guarantee. Other shortages of PVA implants are their low mechanical properties incomparable with natural hard tissues.

Application of implants based on sintered calcium phosphate ceramics like hydroxyapatite $\left(\mathrm{Ca}_{10}\left(\mathrm{PO}_{4}\right)_{6}(\mathrm{OH})_{2}\right)$ for bone and dental reconstruction is worldwide known because of their excellent biocompatibility (Wozney et al. 1998, Suchanek et al., 1998, Vitkovič et al., 2009), high osteoconductivity (Ducheyne et al. , 1999) and relative good mechanical properties. It can be used as solid or as injectable gel (Hua et al., 2010). Unfortunately, HA-based implants have limited applications because of their brittleness and poor performance of long term mechanical stability susceptible for the regeneration of non-load-bearing bone defects. Natural HA and synthetic HA can differ in their chemical composition and behavior. It is known that most synthetic HA are stoichiometric, with a chemical composition of $\mathrm{Ca}_{10}\left(\mathrm{PO}_{4}\right)_{6}(\mathrm{OH})_{2}$. By contrast, human bones do not have pure or stoichiometric HA. Human bones contain other ions, mainly $\mathrm{CO}_{3}^{2-}$ and traces of $\mathrm{Na}^{+}, \mathrm{Mg}^{2+}, \mathrm{Fe}^{2+}$, $\mathrm{Cl}^{-}, \mathrm{F}^{-}$. That is why the $\mathrm{Ca} / \mathrm{P}$ molar ratio in bone is lower than 1.67, compared to a molar ratio of $\mathrm{Ca} / \mathrm{P}$ in synthetic HA (Lutišanová et al., 2012). It was reported (Evis et al., 2006) that this ratio can be an important factor in cell adhesion, proliferation and in bone remodeling and formation.

To overcome the shortages of PVA and HA alone as implants, composite polymer bioceramics were intensively developed in the last decade (Pramanik et al, 2008, Ragel et al. 2002, Williams, 2009). The 
synthesized biocomposite materials must be suitably tailored in order to perform some specific functions, for example to improve the mechanical properties of polymer or the toughness of HA. The tremendous amount of researches on biocomposite polymers-ceramics is justified by the fact that bone is an anisotropic composite consisting mainly of organic polymers (collagen and fibrin protein) and inorganic ceramic minerals (poorly crystalline, nonstoichiometric, carbonated or substituted HA). Among a variety of biocomposite materials, hydroxyapatite-polyamide (Wang et al., 2007), hydroxyapatite-polyethylene (Wang et al., 2001), hydroxyapatite-collagen-hyaluronic acid (Bakoš et al., 1999) scaffolds for tissue engineering were prepared.

In reinforced polymer matrix, the principal role is played by the interfacial bond between polymer molecules and fillers. Wang et al. (2001) has reported that this bond depends on the hydrophobicity or polarity of both fillers and polymers.

The mineral of hydroxyapatite present in polymer matrixes provide active sites for biomineralization and also for cellular attachment. It is well established that bioactivity of materials is considered as its ability to form a strong biointegration with host tissue through interface bone-biomaterials due to the formation of bone like hydroxyapatite in vitro or in vivo.

The development of biocomposite materials was motivated by the fact that pure material cannot alone meet all requirements for biomedical implants. Generally, composite material consists at least of two chemically distinct phases which coexist as matrix-filler entity.

Many factors such as type and content of filler in polymer matrix and matrix properties (e.g. molecular weight) have a significant influence upon the properties of composite materials (Wang et al., 2003). In the case of biocomposites, other factors such as biocompatibility of the filler or matrix, the degradation rate of matrix and non-toxicity must be considered.

\section{Experimental}

\section{Materials}

Polyvinylalcohol Mowiol 10-98 with Mw 61000 was purchased from Clariant. Diammonium hydrogen phosphate $\left(\mathrm{NH}_{4}\right)_{2} \mathrm{HPO}_{4}$, calcium nitrate tetrahydrate $\mathrm{Ca}\left(\mathrm{NO}_{3}\right)_{2} \cdot 4 \mathrm{H}_{2} \mathrm{O}$ and ammonium hydroxide $\mathrm{NH}_{4} \mathrm{OH}$ were from Sigma-Aldrich. Distilled water for all the procedures was used.

\section{Samples preparation}

\section{Method of hydroxyapatite preparation}

Diammonium hydrogen phosphate $\left(\mathrm{NH}_{4}\right)_{2} \mathrm{HPO}_{4}$ and calcium nitrate tetrahydrate $\mathrm{Ca}\left(\mathrm{NO}_{3}\right)_{2} \cdot 4 \mathrm{H}_{2} \mathrm{O}$ were mixed in aqueous solution in required ratio $\mathrm{Ca} / \mathrm{P}$ 1.67. The reaction (Equation 1) was kept in alkali environment at $\mathrm{pH}$ value 9 by ammonium hydroxide solution.

These conditions and intensive stirring lead to gelation of solution. Then, the gel was washed many time with distilled water and $\mathrm{pH}$ measurements were taken until the gel $\mathrm{pH}$ was neutral, so all the ammonium ions were washed out.

Via this reaction fine hydroxyapatite particles was synthetized:

$$
\begin{gathered}
6\left(\mathrm{NH}_{4}\right)_{2} \mathrm{HPO}_{4}+10 \mathrm{Ca}\left(\mathrm{NO}_{3}\right)_{2} \cdot 4 \mathrm{H}_{2} \mathrm{O}+8 \mathrm{NH}_{4} \mathrm{OH} \rightarrow \\
\rightarrow \mathrm{Ca}_{10}\left(\mathrm{PO}_{4}\right)_{6}(\mathrm{OH})_{2}+20 \mathrm{NH}_{4} \mathrm{NO}_{3}+20 \mathrm{H}_{2} \mathrm{O}
\end{gathered}
$$

\section{Preparation of membranes}

Clariant polyvinylalcohol was dissolved in distilled water under constant stirring at the temperature $85^{\circ} \mathrm{C}$ for 4 hours until all solid polymer was dissolved. The amount of polymer used was $21 \mathrm{~g}$ dissolved in $400 \mathrm{ml}$ of distilled water. Homogenized solutions with various PVA: HA ratios were poured into a mold. They were dried during 7 days at temperature $30{ }^{\circ} \mathrm{C}$ in laboratory own to obtain $1 \mathrm{~mm}$ thin membranes

\section{Bioactivity testing}

The assessment of in vitro bioactivity of samples was carried out by soaking the membranes in $40 \mathrm{ml}$ SBF, as proposed by Kokubo et al. (1991). Value of $\mathrm{pH}$ was 7.32 and temperature $37.50 \pm 1^{\circ} \mathrm{C}$. The ion composition of simulated body fluid (Table 1.) is nearly equal to inorganic ion concentrations of human blood plasma and it was prepared according to the literature (Kokubo, 2006).

Cleaned samples of size $1 \times 1 \mathrm{~cm}$ were immersed and stored in the incubation apparatus (Binder BD 115) for 2 hours, 7 and 28 days at the temperature of $37.0^{\circ} \mathrm{C}$. The microstructure of membranes

Tab. 1. The ion concentrations (mol/l) of SBF in comparison with ions in human blood.

\begin{tabular}{lcccccccc}
\hline & $\mathbf{N a}^{+}$ & $\mathbf{K}^{+}$ & $\mathbf{M g}^{2+}$ & $\mathbf{C a}^{2+}$ & $\mathbf{C l}^{-}$ & $\mathbf{H C O}_{3}^{-}$ & $\mathbf{H P O}_{4}^{2-}$ & $\mathbf{S O}_{4}^{2-}$ \\
\hline Blood plasma & 142.0 & 5.0 & 1.5 & 2.5 & 103.0 & 27.0 & 1.0 & 0.5 \\
SBF & 142.0 & 5.0 & 1.5 & 2.5 & 148.8 & 4.2 & 1.0 & 0.5 \\
\hline
\end{tabular}


surface was tested before and after soaking in SBF by SEM.

\section{SEM}

The surface morphology was examined using scanning electron microscope JEOL JSM-7600F. The surface of biocomposite membranes after soaking in SBF was analyzed by SEM (TESLA BS 300) to detect the structure and homogeneity of the composites.

\section{Infrared spectroscopy}

Infrared spectra of composite materials were recorded by Spectrometer Thermo Nicolet iS10 (Thermo Scientific) using $\mathrm{KBr}$ pellets technique. Pellets were prepared by pressing the mixture of precursor and dry $\mathrm{KBr}$ with the mass ratio 1:100. All spectra were recorded in the wavenumber range from 4000 to $500 \mathrm{~cm}^{-1}$.

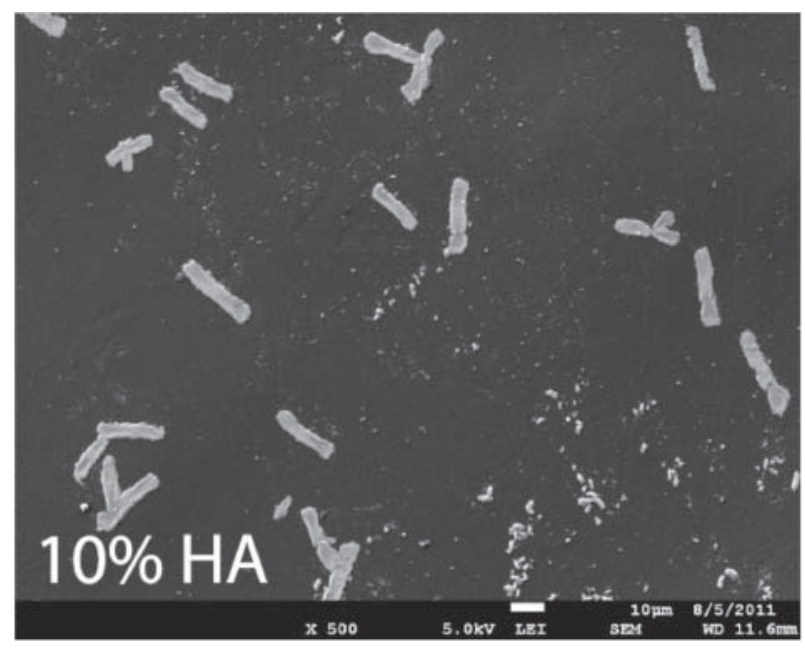

Fig. 1. Microstructure of PVA/HA composite with $10 \% \mathrm{HA}$ in PVA matrix.

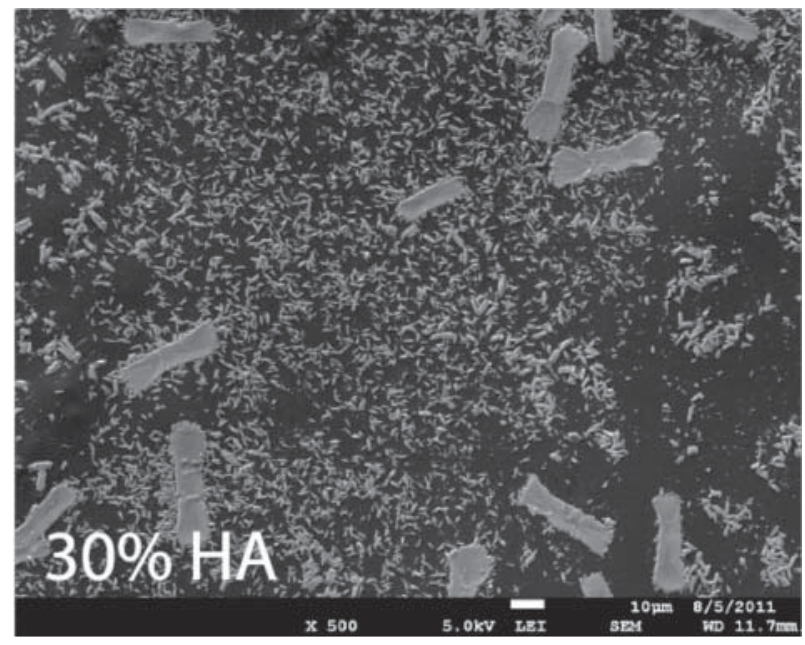

Fig. 3. Microstructure of PVA/HA composite with $30 \% \mathrm{HA}$ in PVA matrix.

\section{Results and discussion}

\section{SEM}

The SEM images of PVA-HA composites at 500 magnification are displayed in Fig. 1-5. The pure PVA membrane was clear. The PVA matrix was uniform without bubbles (not represented in the manuscript). Hydroxyapatite in composite is present in rod-like particles, which create various structures - agglomerates. The PVA membrane with $10 \%$ of HA shows needles of HA dispersed within the membrane. Sample PVA with $20 \%$ HA contains differently shaped agglomerates from $10 \%$ HA sample. Short agglomerated clusters of HA needles and plenty of HA needles distributed itself in the PVA matrix were found in this samples. The $30 \%$ PVA-HA sample contains HA of similar structures as in sample with $10 \%$ of HA, but dispersed within needles ones. The $40 \%$ HA sample shows that the

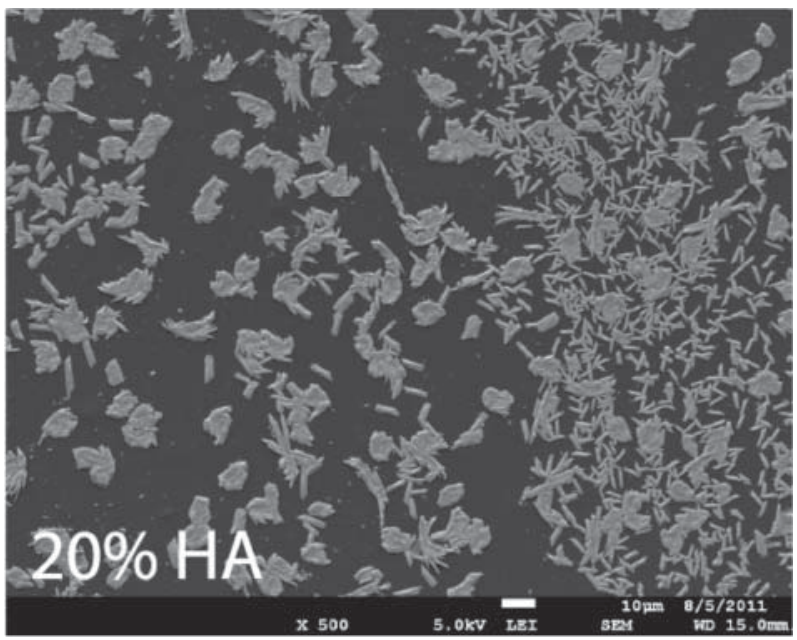

Fig. 2. Microstructure of PVA/HA composite with 20 \% HA in PVA matrix.

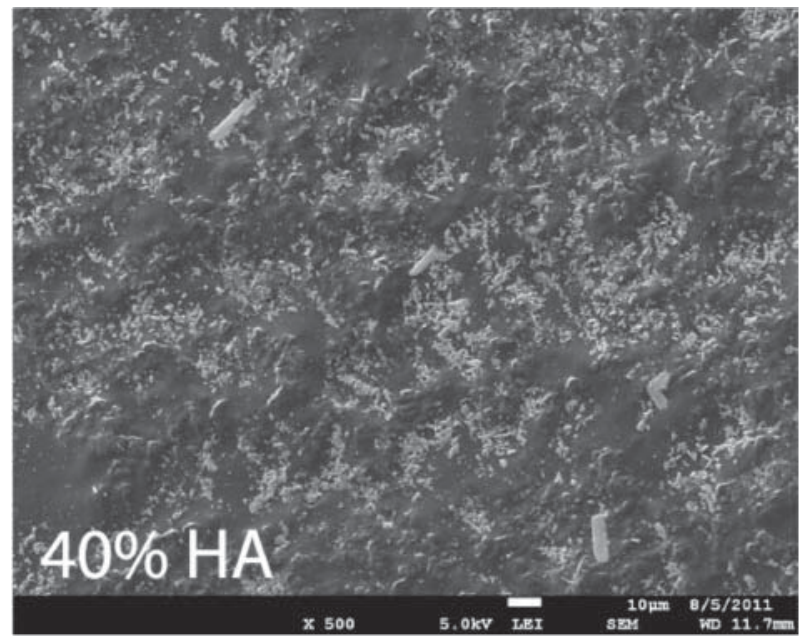

Fig. 4. Microstructure of PVA/HA composite with $40 \% \mathrm{HA}$ in PVA matrix. 


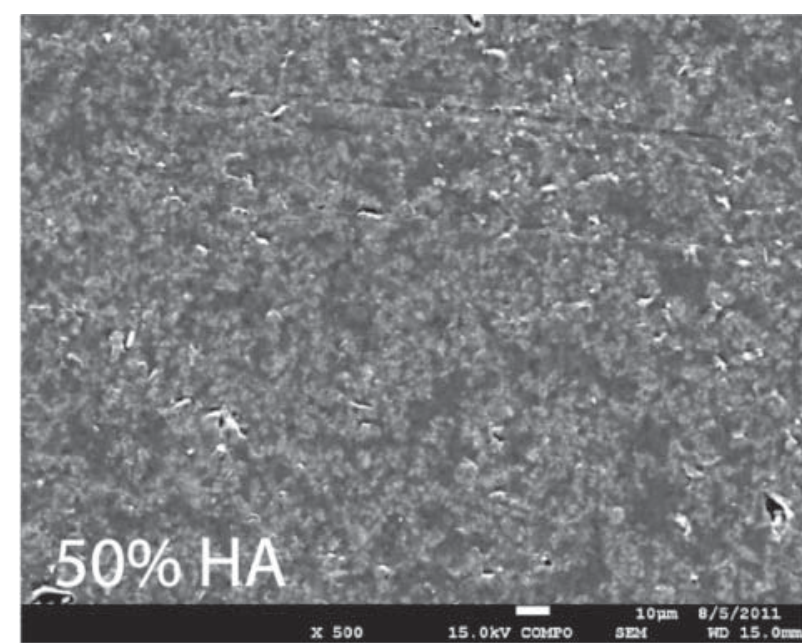

Fig. 5. Microstructure of PVA/HA composite with $50 \%$ HA in PVA matrix.

matrix is saturated with the HA filler. The HA is dispersed all over the testing area and obviously the HA grows into the surface of the membrane and causes its roughness. The $50 \%$ HA shows huge agglomerates, which grow through the surface and made the specimen very rough. Hydroxyapatite particles were of nanometer size, which is shown in Fig. 6. The change in morphology and size of HA particle due the crystal growth of nanoparticles is related not only to the concentration, but to the action of temperature $\left(37^{\circ} \mathrm{C}\right)$ and time of preparation (7 days).

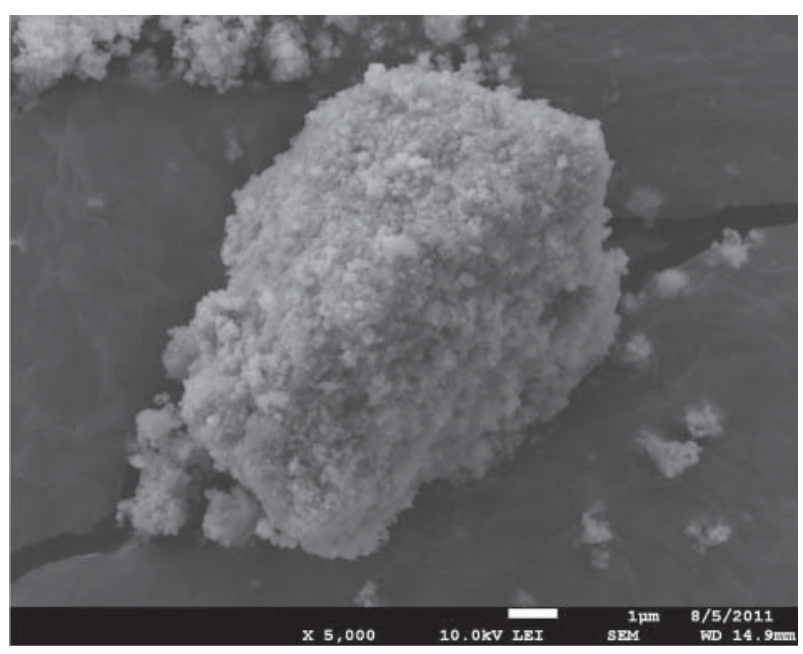

Fig. 6. Shows detailed view of HA nano particles at 5000 magnification.

\section{FTIR Characteristic}

The FTIR of different biocomposite membranes are depicted in Fig. 8. The FTIR spectra are aligned from pure PVA to PVA with 50 wt. \% HA. The spectrum shows several bands characteristic of stretching and bending vibrations of different functional groups like $\mathrm{O}-\mathrm{H}, \mathrm{C}-\mathrm{H}, \mathrm{C}=\mathrm{C}$ and $\mathrm{C}-\mathrm{O}$ groups.

The results show an increasing intensity of absorbance varying with the amount of HA in the samples in the adsorption range from $3000 \mathrm{~cm}^{-1}$ to $3500 \mathrm{~cm}^{-1}$. Broad and strong band at $3360 \mathrm{~cm}^{-1}$ which characterizes $\mathrm{O}-\mathrm{H}$ stretching frequency is well detected

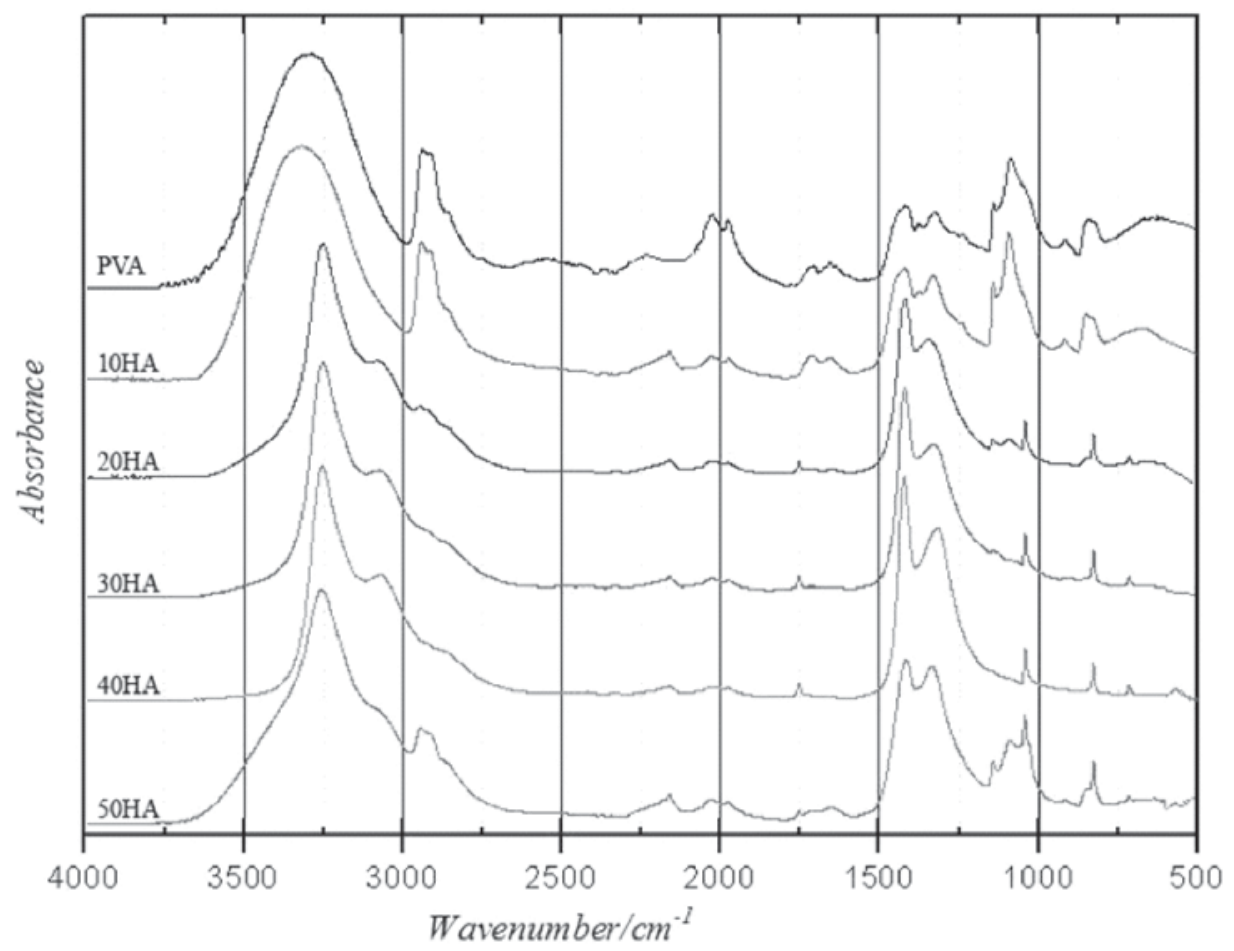

Fig. 7. FTIR spectra of pure PVA and PVA-HA composites. 


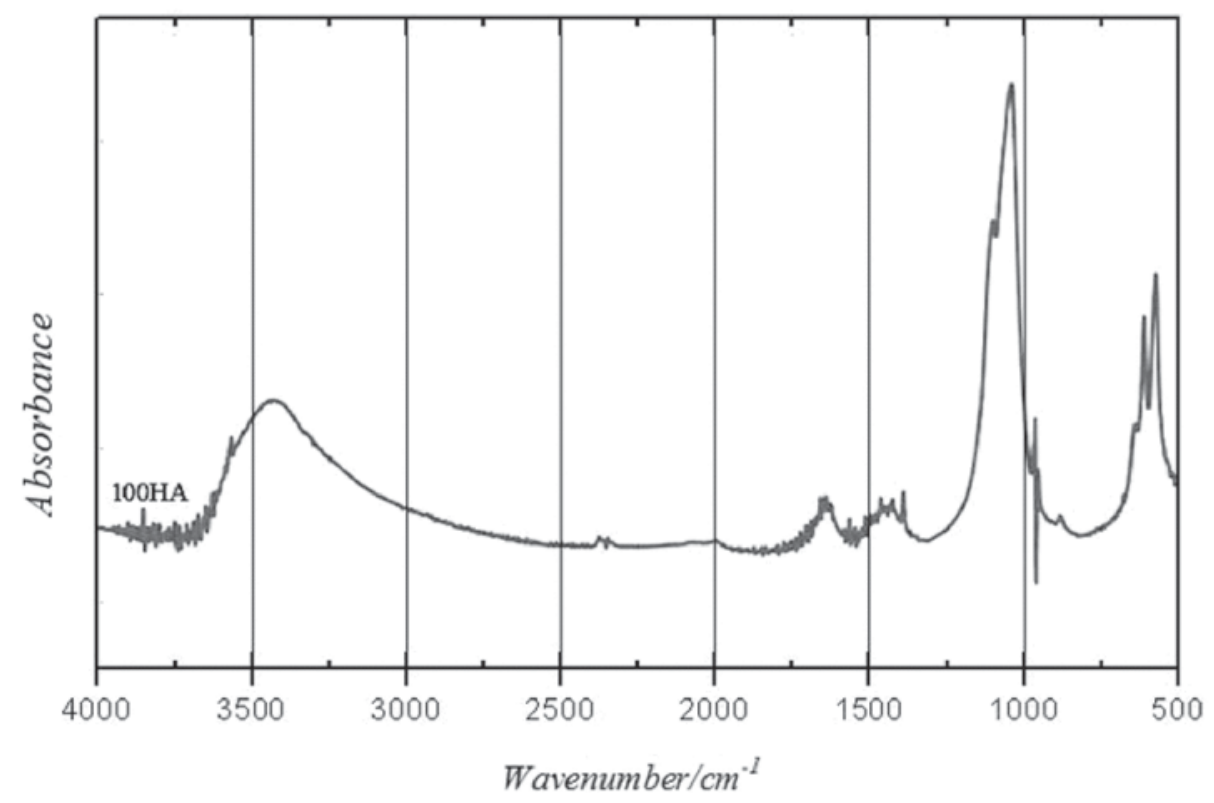

Fig. 8. FTIR spectrum of pure HA powder.

due the increasing presence of $\mathrm{HA}$ in composite materials.

The PVA spectrum indicates a wide and intense band due to the presence of hydroxyl groups $(\mathrm{O}-\mathrm{H})$ at $3441 \mathrm{~cm}^{-1}$. The bands corresponding to the $\left(-\mathrm{CH}_{2}-\right)$ asymmetric and the symmetric stretching at around $2800 \mathrm{~cm}^{-1}$. The band at $1400 \mathrm{~cm}^{-1}$ can be attributed to $\mathrm{O}-\mathrm{H}$ and $\mathrm{C}-\mathrm{H}$ bending. The absorption peaks at $1110 \mathrm{~cm}^{-1}$ are related to $\mathrm{C}-\mathrm{O}$ stretching.

The band at $900 \mathrm{~cm}^{-1}$ results from an angular deformation outside the plan of $\mathrm{O}-\mathrm{H}$ bond. The absorption bands at $1625 \mathrm{~cm}^{-1}$ is due to symmetric

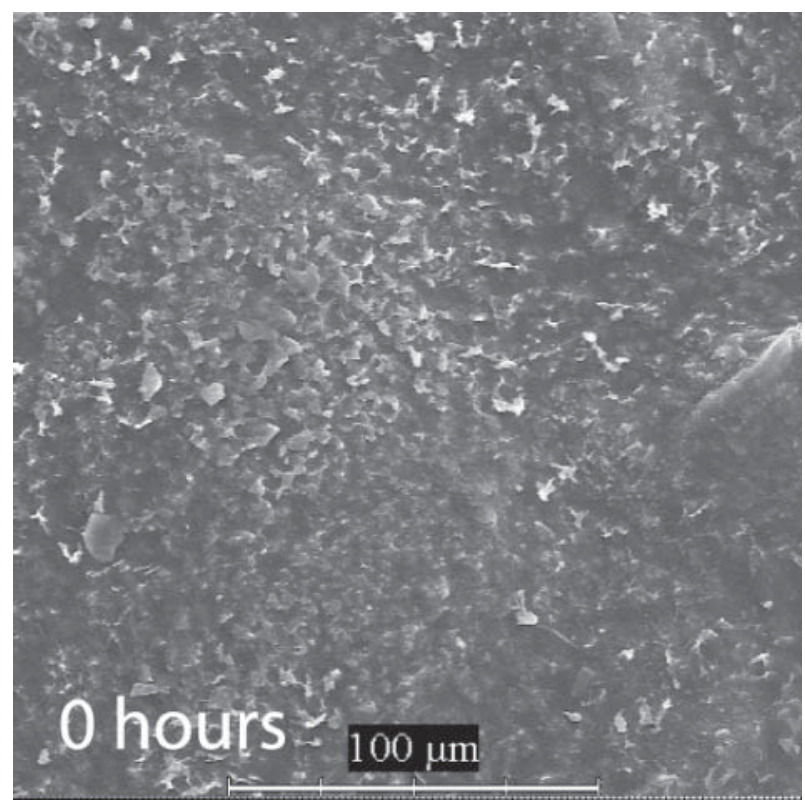

Fig. 9. Surface morphology of composite (50 \% HA in PVA matrix) coatings before soaking in SBF. stretching of carboxylate anion (- $\mathrm{COO}-$ ) (Wang et al., 2004).

The intensity of spectrum at around $1330 \mathrm{~cm}^{-1}$ increases with increasing content of $\mathrm{HA}$ in samples and is assigned to the phosphate group $\mathrm{PO}_{4}{ }^{3-}$. It seems that the intensity of the main peaks decreases while that of appearing one increases due to the decreasing amount of PVA in composite materials. These bands have been attributed to the stretching mode of $\mathrm{C}-\mathrm{O}$ and $\mathrm{C}-\mathrm{C}$ groups.

Fig. 7 shows spectrum of pure HA powder. Bands at 630 and $3570 \mathrm{~cm}^{-1}$ indicate structural $\mathrm{O}-\mathrm{H}$

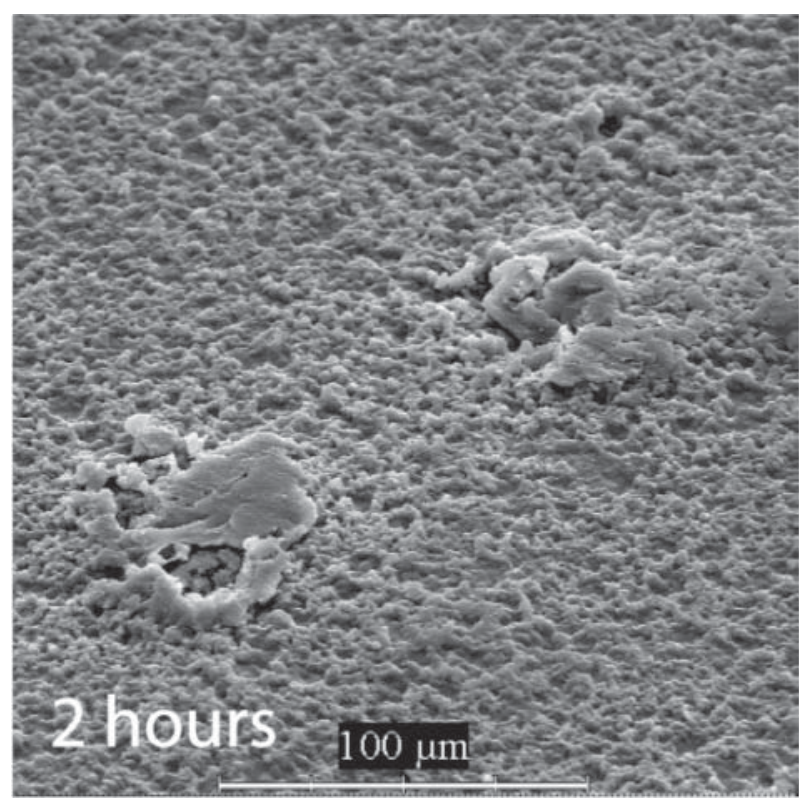

Fig. 10. Surface morphology of composite (50 \% HA in PVA matrix) coatings after soaking in SBF for 2 hours. 


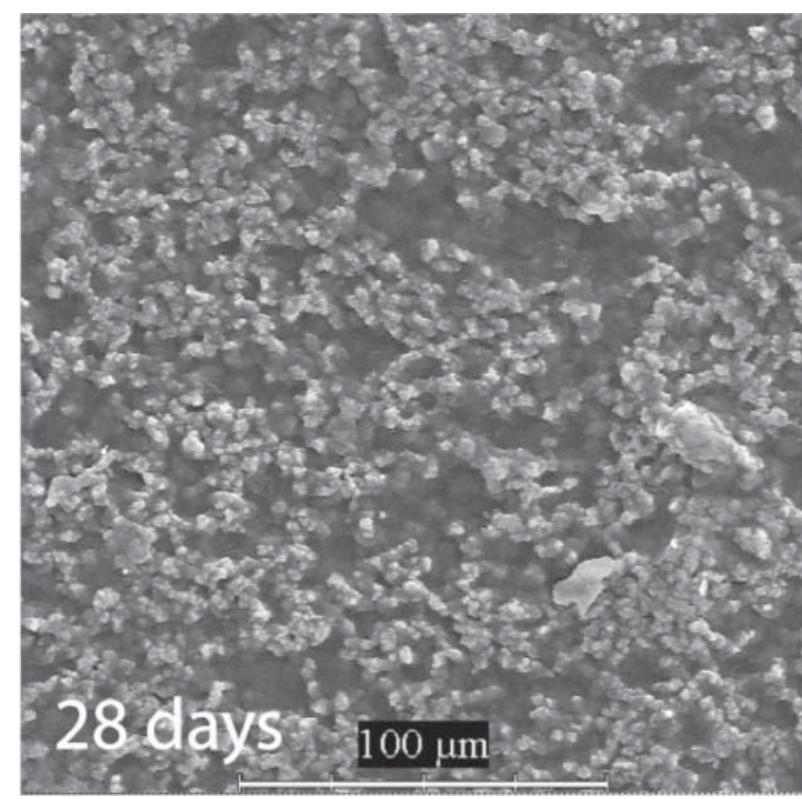

Fig. 11. Surface morphology of composite (50 \% HA in PVA matrix) coatings after soaking in SBF for 28 days.

groups in the n-HAp crystals. Bands located at about $1000-1100$ and $560-570 \mathrm{~cm}^{-1}$ are attributed respectively to the $v 3$ and $v 4 \mathrm{P}-\mathrm{O}$ vibration modes of regular tetrahedral $\mathrm{PO}_{4}^{3-}$ groups.

The observed bands at $604 \mathrm{~cm}^{-1}$ corresponds to $\mathrm{O}-\mathrm{P}-\mathrm{O}$ bending and $v 1$ symmetric $\mathrm{P}$ stretching modes. The $v 1$ symmetric stretching mode of phosphate group is observed at $957 \mathrm{~cm}^{-1}$. The observed bands at $1391 \mathrm{~cm}^{-1}$ is due to the stretching mode of carbonate, which may be to the acquisition of air during mineral precipitation (Rajkumar et al. 2010). Band at $1641 \mathrm{~cm}^{-1}$ indicates the presence of $\mathrm{H}_{2} \mathrm{O}$ in HAp crystals (Pramanik et al. 2008)

\section{Bioactivity Testing}

The pictures display formation of HA on the surface of $50 \%$ HA composite during testing periods. The in vitro testing proved the bioactive properties of the PVA-HA composite.

A very small amount of HA crystals were found on pure PVA membrane after soaking in SBF for 28 days. However, the crystals were observed on all composite membranes just after 2 hours of soaking in SBF. Most of the membranes surface was entirely covered with crystals after 7 days of soaking in SBF. The formation of the mineral layer was similar in the case of other composite materials.

\section{Conclusion}

Polyvinyl alcohol-hydroxyapatite membranes were prepared with various amounts of hydroxyapatite. These composites were examined by SEM, FTIR.

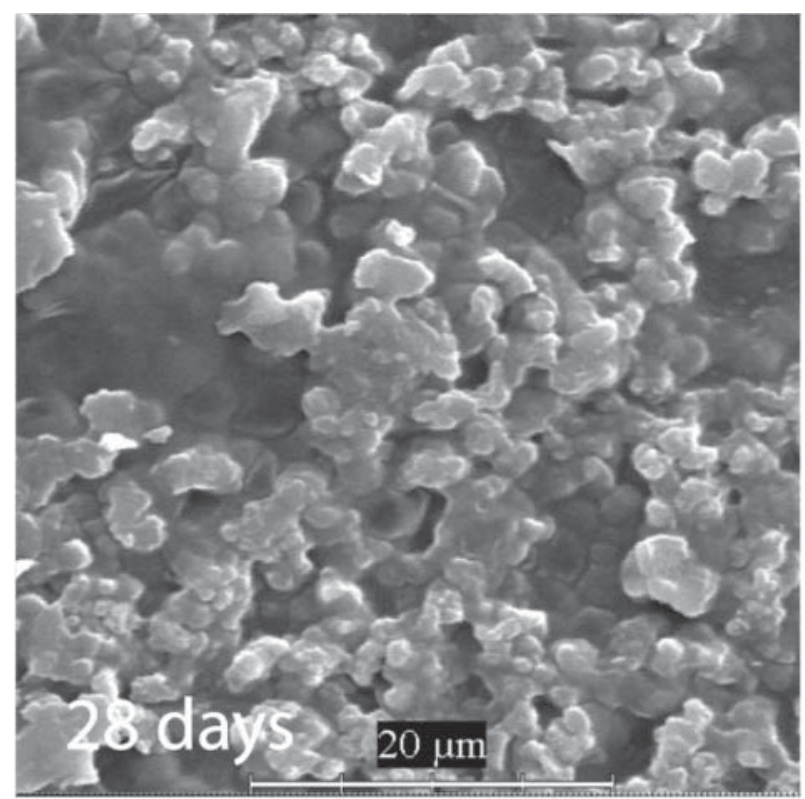

Fig. 12. Detail of new formed hydroxyapatite on the surface.

Bioactivity was tested by soaking in SBF. With increasing content of HA in samples, membranes become more inhomogeneous and larger crystal of HA were observed due to the crystallization process during drying. The bioactivity of membrane containing $50 \%$ of HA increased with increasing soaking time. Coarser particles of new apatite are observed on the surface of composite materials. The formation of apatite layer on the surface of the composites after soaking in SBF demonstrates high in vitro bioactivity of tested samples, what makes the composite suitable candidate for applications as artificial cartilage.

\section{Acknowledgements}

This work was supported by Project Centers for materials research at FCH BUT, reg. no. CZ.1.05/2.1.00/01.0012. This work was also supported by the VEGA grant No. 1/0934/11.

\section{References}

Bakoš D, Soldan M, Hernandez-Fuentes I (1999) Biomaterials 20: 191-195.

Covert RJ, Ott RD, Ku DN (2003) Wear 255, 1064-1068. Chen F, Wang ZCH, Lin CHJ (2002) Materials Letters 57: 858-861.

Ducheyne P, Qiu Q (1999) Biomaterials 20: 2287-303.

Evis Z, Sato M, Webster TJ (2006) Journal of the Biomedical Materials Research 78(3): 500-507.

Hua L, Xia FCH, Chang RZ (2010) Key Engineering Materials, 434-435: 590-593.

Kobayashi M, Chang YS, Oka M (2005) Biomaterials 26: 3243-3248.

Kokubo T (1991) Biomaterials 12: 155-63. 
Kokubo T, Takadama H (2006) Biomaterials 27(15): 2907-2915.

Lutišanová G, Palou MT, Kozánková J (2011) Ceramics - Silikáty 55(3): 199-207. Noguchi T, Yamamuro T, Oka M (1991) Journal of Applied Biomaterials 2(2): 101-107.

Pan YS, Xiong DS, Ma RY (2007) Wear 262: 1021-1025.

Pramanik N, Mohapatra S, Alam S (2008) Polymer Composites 29: 429-436.

Ragel CV, Vallet-Regi M, Rodriguez-Lorenzo LM Biomaterials 23: 1865-1872.

Rajkumar M, Sundaram MN, Rajendran V (2010) International Journal of Engineering Science and Technology 2(6): 2437-2444.

Suchanek W, Yoshimura M (1998) Journal of Materials Research 13, 94-117.

Vallet-Regi M (2010) Comptes Rendus Chimie 13: $174-185$.
Vitkovič M, Maha SMN, Palou M, Jantová S (2009) Central European Journal of Chemistry 7(2): 246-251.

Wang RZ, Cui FZ, Lu HB, Wen HB, Ma CL, Li HD (1995) Journal of Materials Science Letters 14: 490-492.

Wang M, Deb S, Bonfield W (2001) Biomaterials 11: $1311-1320$.

Wang M (2003) Biomaterials 24: 2133-2151.

Wang T, Turhan M, Gunasekaran S (2004) Polymer International 53: 911-918.

Wang H, Li Y, Zuo Y, Li J, Ma S, Cheng L (2007) Biomaterials 28: 3338-3348.

Williams DF (2009) Biomaterials 30: 5897-5909.

Wozney JM, Rosen V (1998) Clinical Orthopaedics and Related Research 346: 26-37.

Zheng QG, Jiu MX, Xiang HZ (1998) Bio-Medical Materials and Engineering 8: 75-81. 